\title{
Análisis histórico-social de los Consultorios Jurídicos. Balance del Consultorio Jurídico de la UPTC en el Área Laboral (2018-2019)
}

Social Historical Analysis of Legal Clinics. Balance of the UPTC Legal Clinic in the Labour Area 2018-2019

Autores: Nury Yohana Zipa-Vargas, Luis Carlos Cepeda Villar y Yair Leonardo Fonseca Alfonso

Para citar este artículo:

Zipa-Vargas, N., Cepeda Villar, L. y Fonseca Alfonso, Y. (2021). Análisis históricosocial de los Consultorios Jurídicos. Balance del Consultorio Jurídico de la UPTC en el Área Laboral 2018-2019. Derecho y Realidad, 19 (38), 165-186.

Derecho y Realidad | ISSN Impreso 1692-3936 | ISSN En línea 2619-5607

Vol. 19 - Número 38 Julio - Diciembre de 2021 | pp. 165 - 186 DOI: https://doi.org/10.19053/16923936.v19.n38.2021.13697

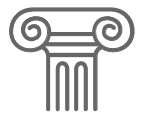




\section{ANÁLISIS HISTÓRICO-SOCIAL DE LOS CONSULTORIOS JURÍDICOS. BALANCE DEL CONSULTORIO JURÍDICO DE LA UPTC EN EL ÁREA LABORAL (2018-2019)*}

Social Historical Analysis of Legal Clinics. Balance of the UPTC Legal Clinic in the Labour Area 2018-2019

\section{Nury Yohana Zipa-Vargas}

Abogada de la Facultad de Derecho y Ciencias Sociales de la Universidad Pedagógica y Tecnológica de Colombia -UPTC-.

yohanazipa@gmail.com

\section{Luis Carlos Cepeda Villar}

Facultad de Derecho y Ciencias Sociales de la Universidad Pedagógica y Tecnológica de Colombia. Actualmente realiza judicatura como modalidad de grado. Cuenta con un diplomado en Introducción a la Ciencia Política de la UNAD. Redactor Revista Llano Adentro.

luiz_cepeda@hotmail.com

\section{Yair Leonardo Fonseca Alfonso}

Abogado, Magíster en Derecho-Profundización en Derecho del Trabajo. Docente Catedrático Externo de la Universidad Pedagógica y Tecnológica de Colombia -UPTC-.https://orcid.org/0000-0002-7717-1321 yair.fonseca@uptc.edu.co

Recepción: Abril 11 de 2021

Aceptación: Junio 2 de 2021

\section{RESUMEN}

Este artículo de investigación, mediante un método inductivo con enfoque cuantitativo, realizó un análisis histórico-social de los consultorios jurídicos tanto a nivel internacional como desde el punto de vista nacional. A partir de lo anterior, se estableció como objetivo principal de investigación, hacer un estudio detallado y verídico, con base en información concreta y real, de la efectividad del Consultorio Jurídico Armando Suescún Monroy de la Universidad Pedagógica y Tecnológica de Colombia, en relación con el acceso a la justicia, particularmente en el Área
Laboral, por ser de interés público y de vital trascendencia para las poblaciones vulnerables dentro del marco de su competencia.

Los resultados obtenidos en la presente investigación, han sido concluyentes y motivo de reflexión. La mayoría de los usuarios, después de un largo lapso, desiste de sus pretensiones; los procesos que llegan a la jurisdicción son pocos, lo cual lleva a concluir que la función del consultorio está quedando en una simple formalidad.

* Artículo producto del Semillero de Investigación Ignacio Torres Giraldo. 


\section{PALABRAS CLAVES}

Consultorio jurídico; acceso a la justicia; vulnerabilidad; derechos; formación práctica; derecho laboral.

\section{ABSTRACT}

This research article using an inductive method with a quantitative approach carried out a historical social analysis of legal clinics, both internationally and from a national point of view. From the above, it was established as the main research objective to make a detailed and truthful study based on concrete and real information of the effectiveness of the legal clinic Armando Suescún Monroy from the Pedagogical and Technological University of Colombia, in regard to access to justice, particularly in the area of labour law, because it is of public interest and vital importance for vulnerable populations within the framework of their competence.

The results obtained in this research have been conclusive and cause for reflection. Most users after a long lapse withdraw their claims, the processes that enter the jurisdiction are few, which leads to the conclusion that the function of the legal clinic is being left in a simple formality.

\section{KEYWORDS}

Legal clinic; access to justice; vulnerability; rights; practical training; labour law.

\section{INTRODUCCIÓN}

En Colombia acceder a la justicia sigue siendo toda una hazaña para aquellos que se encuentran en situaciones de mayor vulnerabilidad, a pesar de que este derecho universal se ha consagrado como uno de los pilares de la Constitución Política, la cual se manifiesta como ente regulador de las relaciones humanas y soporte pacificador del pacto social. Su aplicabilidad permite no solo el cumplimiento de sus fines, sino que además conlleva la satisfacción de un sinnúmero de derechos.
Por consiguiente, se han establecido políticas gubernamentales como la implementación de los consultorios jurídicos, buscando dar cumplimiento a los cometidos de todo Estado Social de Derecho y específicamente con el fin de garantizar el acceso efectivo a la administración de justicia a las personas de bajos recursos o en condiciones de vulnerabilidad. Actualmente, estas instituciones tienen un papel importante en la garantía del derecho en mención; así lo concluyen La Rota et al. (2014) al indicar que estos centros representan un tercio de los abogados que prestan sus servicios a las personas en situación de pobreza extrema. No obstante, de acuerdo con Recalde et al. (2017), los consultorios se han convertido en espacios ritualistas donde prima la forma sobre la sustancia, por lo que no están logrando materializar el derecho al acceso a la justicia de las personas de bajos recursos socioeconómicos.

Con la finalidad de proyectar propuestas de cambio, en este texto se presenta un estudio sobre el Consultorio Jurídico Armando Suescún Monroy de la Universidad Pedagógica y Tecnológica de Colombia UPTC- y se analiza su efectividad en relación con el acceso a la justicia de los usuarios del área laboral entre 2018 y 2019, por la particular relevancia que tienen los conflictos de esta jurisdicción "por tratarse de asuntos de interés social general y por la desigualdad económica, de cultura y de medios de defensa, que existe entre las partes" (Echandía, 2012, p.108).

En tal sentido, para desarrollar este trabajo se formuló la siguiente pregunta de investigación: ¿El Consultorio Jurídico de la UPTC garantizó durante 2018 y 2019 el acceso efectivo a la administración de justicia a sus usuarios del área de derecho laboral?

Correlativamente, como hipótesis se pretende validar que la labor de este centro se está quedando en lo meramente formal. Por ende, se está dejando de lado la garantía de acceso efectivo a la administración de justicia. 
En Colombia, no existe una regulación adecuada, ni políticas públicas acordes a la realidad social de aquellas personas en situación de vulnerabilidad que buscan acceder a la justicia, siendo pertinente recordar que "si alguien es titular de un derecho, pero carece de la posibilidad de reclamarlo... en realidad carece del derecho que le ha sido teóricamente reconocido" (La Rota, et al., 2014, p.13).

En función de lo planteado, esta investigación se desarrolla así: el primer capítulo, estudia desde un punto de vista conceptual e histórico el origen de los consultorios jurídicos, tanto en América Latina como en Colombia; en el segundo capítulo se exponen los fundamentos normativos y jurisprudenciales, con especial énfasis en el derecho de acceso a la administración de justicia. En el tercer capítulo, mediante un método inductivo con enfoque cuantitativo, se analiza el desempeño del consultorio de la UPTC respecto a la garantía de acceso a la justicia y, por último, se presentan las conclusiones de esta investigación y algunas recomendaciones en procura del mejoramiento del servicio y corrección de las falencias que se puedan estar presentando.

\section{ORIGEN DE LOS CONSULTORIOS JURÍDICOS}

Resulta imperativo comenzar precisando qué es un consultorio jurídico, con el objetivo de entender sus funciones y finalidades. Pues bien, los consultorios jurídicos son instituciones que prestan servicios jurídicos gratuitos a personas de bajos recursos económicos, con el objetivo de garantizar su derecho al acceso a la administración de justicia, mediante un acompañamiento jurídico en procesos laborales, civiles, penales, disciplinarios y fiscales.

En palabras de Duque et al. "los consultorios jurídicos se conciben como un servicio legal para los más pobres y como una forma de reivindicar la labor social del abogado y de las facultades de derecho" (2012, p. 292); y, según Bonilla (2018), se describen como un espacio académico que busca que los estudiantes desarrollen destrezas necesarias para ser profesionales competentes del derecho. Adicionalmente, este último autor indica que los consultorios se pueden clasificar por el tipo de cliente al que usualmente sirven, encontrándose los que laboran para clientes individuales; los que se enfocan en comunidades y los que sirven a organizaciones sociales. Así mismo, se pueden clasificar de acuerdo con la temática: nacional o internacional; así como por la duración: corto tiempo con un solo individuo o a largo plazo con comunidades.

Ahora bien, aunque algunos autores suelen hacer semejanza entre Consultorio Jurídico y Clínica Jurídica, no son lo mismo. De manera acertada Villarreal (2013) aclara la diferencia , con las siguientes palabras:

Es precisamente la defensa del interés público el aspecto que marca la diferencia entre las clínicas jurídicas y los Consultorios Jurídicos que tradicionalmente han existido en Colombia por mandato legal, los cuales, si bien implican la presencia de estudiantes de derecho asumiendo causas jurídicas reales, se centran en las áreas tradicionales del derecho y en el manejo de causas individuales; mientras que las clínicas jurídicas han evolucionado hacia un esquema que procura por la búsqueda de la justicia social por medio del acceso de los grupos menos favorecidos y las colectividades vulnerables a la administración de justicia, el manejo de casos de alto impacto social, la estructuración de casos paradigmáticos y la enseñanza a los grupos vulnerables de sus derechos y la forma de protegerlos, lo que evidencia la importancia de la defensa del interés público en la enseñanza del derecho. (p. 718)

Sin embargo, los consultorios jurídicos en el desarrollo de sus actividades "pueden atravesar los límites que diferencian estas taxonomías. Así, por ejemplo, un consultorio jurídico puede al mismo tiempo pretender solucionar casos individuales y estructurales y tener como clientes tanto a comunidades 
como a individuos y organizaciones sociales" (Bonilla, 2018, pp. 59-60).

En efecto, en la práctica se ve que muchos consultorios, como medio de llegar también a las comunidades, han establecido el desarrollo de clínicas jurídicas transitorias, por lo que los estudiantes además de adelantar procesos individuales, también desarrollan investigaciones y proyectos que benefician a determinadas comunidades.

Retomando la conceptualización, la esencia de los consultorios jurídicos consiste en "formar a estudiantes en habilidades profesionales y en deontología profesional, al tiempo que se ofrecen servicios jurídicos a personas en riesgo de exclusión social o sin capacidad económica". (García-Añón, 2014, p. 27)

\subsection{Creación en Latinoamérica y Colombia}

De acuerdo con Bonilla (2018), los consultorios jurídicos se crearon en las primeras décadas del siglo $\mathrm{XX}$ en Estados Unidos, como herramienta para contrarrestar la educación jurídica formalista $y$ buscaban garantizar una adecuada formación profesional a través de la experiencia como método de aprendizaje y, a su vez, se ayudaría a proporcionar a las minorías el acceso a la justicia.

En cuanto a Latinoamérica, describe Thome (1984), que "los servicios legales financiados o subvencionados por el estado no existieron de manera consistente sino hasta la década de 1930. Un periodo marcado por gobiernos populistas y nacionalistas" (p.527). Agrega el mismo autor, que la prestación de los servicios era insuficiente y los potenciales beneficiarios no tenían la posibilidad de ejercer sus derechos o aprovechar los beneficios de los programas. Para las personas de menos recursos era difícil entender los requisitos y el complejo procedimiento administrativo.

En consecuencia, a pesar de que en las siguientes décadas hubo un notable crecimiento de los programas de asistencia legal, estos seguían siendo insuficientes para contrarrestar los conflictos y problemas políticos que enfrentaban en aquella época las sociedades de América Latina. Lo anterior, coincidió con:

una época en que Estados Unidos intentaba promover su marca de desarrollo económico y social en todo el Tercer Mundo. Se crearon nuevos programas e instituciones, como el Cuerpo de Paz y el Banco Interamericano y los gobiernos fueron presionados a promulgar reformas agrarias $y$ educativas $y$ otros programas de bienestar social. Para Latinoamérica y el Caribe estos programas se denominaron Alianza para el Progreso (Thome,1984, p. 529).

En ese panorama surgieron los consultorios jurídicos en América Latina, con similar origen: la alianza para el progreso como bandera; el liderazgo de la Agencia de Cooperación Internacional Estadounidense (USAID) y de la Fundación Ford; el patrocinio, entre otros, de un grupo de universidades norteamericanas (Yale, Harvard, la Universidad de Wisconsin y Stanford); y la buena recepción de algunas universidades, como es el caso de la Universidad de los Andes en Colombia. (Castro-Buitrago et al., 2011).

Por su parte, en Colombia por aquellas épocas abundaban los famosos leguleyos, rábulas y tinterillos ${ }^{1}$ y había escasez de verdaderos litigantes, ya que los egresados de la época salían sin ningún tipo de experiencia. Por ello, en el país desde la década de los sesenta ya existía un común acuerdo sobre la necesidad de modificar los métodos de enseñanza del Derecho. Entre los que pregonaban la necesidad de

1. "Los leguleyos, sujetos que sabían de memoria las leyes, pero que ignoraban los principios de la jurisprudencia; los tinterillos, sujetos que comenzaron los estudios de jurisprudencia pero no los terminaron pero conocían de las leyes y su práctica; los rábulas, sujetos que conocían algo de la rutina forense pero que ignoraban del todo las leyes y los principios de la jurisprudencia... Los rábulas, leguleyos y tinterillos existieron en todos los pueblos y absorbieron las funciones que de antaño eran reservadas, única y exclusivamente, a los abogados". (González, s.f., pp.6-7) 
un nuevo rumbo, se destaca al maestro Gaviria Diaz (1968, citado en González, s.f.) quien señalaba que una función indiscutible de la Universidad -en especial en los países subdesarrollados-, es capacitar profesionales que se hagan cargo de las necesidades urgentes de la comunidad.

Ante tal escenario, enhorabuena se expidió el Estatuto del Abogado y con este llegaron los consultorios jurídicos a Colombia, "fueron importados por las elites jurídicas y políticas colombianas durante los gobiernos de Carlos Lleras Restrepo y Misael Pastrana Borrero y exportados por las élites jurídicas estadounidenses durante los gobiernos de John F. Kennedy y Lyndon Johnson." (Recalde, et al., 2017, p.5).

Como resultado, actualmente en Colombia, los consultorios jurídicos funcionan como dependencias de las Facultades de Derecho, que procuran que los ciudadanos de escasos recursos económicos puedan acceder a la administración de justicia. Las competencias que pueden adelantar los estudiantes adscritos a estos centros, se encuentran determinadas en la ley, y a fin de garantizar la idoneidad en la representación, defensa o cualquier intervención a nombre de una persona que carezca de los recursos para acudir a los servicios profesionales de un abogado titulado, se prevé que todas las actuaciones del estudiante se darán bajo la coordinación de los asesores designados y atendiendo las orientaciones del consultorio jurídico.

\section{FUNDAMENTOS NORMATIVOS Y JURISPRUDENCIALES}

Los consultorios jurídicos se han cimentado en el ordenamiento jurídico colombiano, sobre bases con raigambre constitucional, legal y jurisprudencial. A continuación, se exponen los fundamentos jurídicos que soportan la existencia de los consultorios.

\subsection{Fundamentos constitucionales}

Dentro del sustento constitucional de estas instituciones, se encuentran los siguientes preceptos de la Carta Fundamental de 1991:

\subsubsection{Los principios de respeto de la dignidad humana y de la solidaridad}

En el primer artículo de la Constitución establece que Colombia es una república fundada en el respeto de la dignidad humana, así que; "una primera consecuencia de esto es que nunca es lícito negar a una persona su condición de titular de derechos" (Madrid-Malo, 1998, p.45). Claramente, esta consecuencia tiene relación directa con los consultorios jurídicos; pues es función de estas instituciones, el asegurar a las personas de bajos recursos el ser titulares del derecho de acceso a la justicia, el cual implica la consecución de otros derechos.

Por su parte, el principio de solidaridad, también consagrado en el artículo primero de la Constitución de 1991, es guía y finalidad clave de los consultorios, con el acompañamiento judicial que de manera gratuita realizan los estudiantes, se busca ayudar a superar las carencias de los menos favorecidos.

\subsubsection{El derecho a la igualdad y la especial protección de las personas en situación de vulnerabilidad}

El artículo 13 consagra la igualdad ante la ley y establece que el Estado tiene la obligación de propender porque se haga efectiva; asimismo, este artículo indica que es obligación del Estado el brindar especial protección a aquellas personas que se encuentran en situación de debilidad manifiesta. En otras palabras, es motivo de vigencia del Estado Social de Derecho y condición para la existencia de la real democracia, que todos gocen de los mismos derechos (Barreto y Sarmiento, 1997). Siendo ello así, es claro que, respecto a estos cometidos estatales, a los consultorios jurídicos se les ha asignado una importante labor; pues mediante el desarrollo de sus 
actividades ayudan a desarrollar estos postulados.

\subsubsection{Título de idoneidad para el ejercicio de la abogacía}

Con el artículo 26 superior se faculta al legislador para exigir títulos de idoneidad para el ejercicio de una profesión, esta facultad excepcional y limitada del legislador, está orientada a proteger los derechos fundamentales de la comunidad (Barreto y Sarmiento, 1997). Por consiguiente, la práctica que se hace en un consultorio jurídico se constituye en uno de los requisitos esenciales para acreditar la idoneidad de quienes aspiran a obtener el título de abogado. Asimismo, con base en esta facultad, por expresa autorización de la Ley 583 de $2000^{2}$, los estudiantes de derecho adscritos a un consultorio pueden ejercer la abogacía en representación de personas de bajos recursos.

\subsubsection{El derecho fundamental al debido proceso y la defensa técnica}

El derecho al debido proceso se consigna en el artículo 29 constitucional y “comprende un conjunto de principios materiales y formales entre los que se encuentran el principio de legalidad, el principio del juez natural o legal, el principio de favorabilidad penal y el principio de presunción de inocencia". (Sentencia T-572 de 1992). A su vez, uno de los elementos más importantes de este derecho es la defensa técnica, la cual es esencial en el desarrollo de las actividades de los consultorios. Estos centros, a través de sus estudiantes y asesores, deben garantizar a las personas en situación de vulnerabilidad una adecuada defensa, protegiendo así de manera efectiva y eficaz sus derechos, lo cual sería, según Thea (2012), el núcleo esencial del debido proceso.

2. Artículo 1. “(...) Los estudiantes adscritos a los consultorios jurídicos de las facultades de derecho, son abogados de pobres... mientras pertenezcan a dichos consultorios, podrán litigar en causa ajena...."

\subsubsection{El acceso efectivo a la administración de justicia}

El eje fundamental de la existencia de los consultorios jurídicos es quizá el artículo 229 superior; que establece el derecho de toda persona a acceder a la administración de justicia, objetivo último y razón del funcionamiento de los consultorios. Sin embargo, la labor de estos centros no consiste en simplemente permitir a las personas en condición de vulnerabilidad ejercer el derecho de acción. La noción de este derecho ha evolucionado y con base en los tratados sobre derechos humanos hoy se habla de acceso efectivo a la administración de justicia (Silva, 2013).

Lo anterior se traduce en "la posibilidad de que cualquier persona solicite a los jueces competentes la protección o el restablecimiento de los derechos que consagran la Constitución y la ley" (Sentencia C-037 de 1996), pero "no solamente es poner en movimiento el aparato jurisdiccional, a través de los actos de postulación requeridos por la ley procesal, sino en que se surtan los trámites propios del respectivo proceso, se dicte sentencia estimatoria o desestimatoria de las pretensiones de la demanda y que ésta sea efectivamente cumplida" (Sentencia T-268 de 1996).

En tal sentido, según el Máximo Tribunal Constitucional, este derecho tiene un contenido múltiple, del cual se pueden identificar tres categorías: (i) aquéllas que tienen que ver con el acceso efectivo de la persona al sistema judicial; (ii) las garantías previstas para el desarrollo del proceso; y (iii) las que se vinculan con la decisión que se adoptó dentro del proceso en cuestión (Sentencia T-799 de 2011).

De igual forma, este importante derecho se articula con un número significativo de convenios y tratados internacionales que buscan de manera mancomunada su protección y eficacia, entre ellos: la Declaración Universal de los Derechos Humanos (artículos 8 y 10); el Convenio Europeo para la protección de los Derechos Humanos y las Libertades Fundamentales 
(Artículo 13); el Pacto Internacional de Derechos Civiles y Políticos (Artículo 14), siendo particularmente cercano a nuestra definición de acceso efectivo a la justicia, el principio contenido en el inciso primero del artículo 8 de la Convención Americana de Derechos Humanos, el cual establece el derecho de toda persona a ser oída por los jueces, con las debidas garantías y dentro de un plazo razonable, para la determinación de sus derechos y obligaciones de orden civil, laboral, fiscal o de cualquier otro carácter (Silva, 2013).

Lo planteado se sintetiza en que el efectivo acceso a la justicia implica el derecho de toda persona "sin discriminación alguna, a que existan mecanismos adecuados y sencillos del sistema de justicia para la resolución de necesidades jurídicas y sobre las cuales se adopte una decisión mínimamente satisfactoria, oportuna y a la que se le dé cumplimiento" (La Rota et al., 2014, p.31).

\subsection{Fundamento legal}

Desde el punto de vista legal, el cimiento de los consultorios jurídicos empieza con el artículo $30^{3}$ del Estatuto del Abogado (Decreto 196 de 1971), con el cual fueron creados por primera vez en Colombia los consultorios jurídicos. Es necesario aclarar que dicho artículo fue modificado en 2000 por el artículo $1^{\circ}$ de la Ley 583; sin embargo, en cuanto a lo sustancial, esta ley "reitera la calidad de abogados de pobres para los estudiantes adscritos a los consultorios jurídicos de las facultades de derecho, y excluye toda posibilidad de omisión u homologación en lo relativo al deber de prestar el servicio" (Acosta-Madiedo, 2006, p. 161).

Asimismo, el funcionamiento de estas instituciones ha sido reglamentado especialmente con normas como: el Decreto

3. "Las facultades de derecho oficialmente reconocidas organizarán, con los alumnos de los dos (2) últimos años lectivos, consultorios jurídicos cuyo funcionamiento requerirá aprobación del respectivo Tribunal Superior de Distrito Judicial ....".
765 de 1977 , el cual establece sus requisitos de funcionamiento; el Decreto 3200 de 1979 , por el cual se dictan normas sobre la enseñanza del Derecho y por la Ley 941 del 2005, que organiza el sistema de defensoría pública.

De los decretos y leyes referidos, se puede sintetizar lo siguiente:

- Las facultades de Derecho deben organizar consultorios jurídicos con los alumnos de los dos últimos años lectivos.

- El funcionamiento de estos centros requiere de la aprobación del respectivo Tribunal Superior de Distrito Judicial.

- Los estudiantes, según el término legal, actúan como "abogados de pobres".

- La atención en estos lugares es gratuita y orientada a población de estrato 1 y 2 , y excepcionalmente 3 .

- Estos estudiantes hacen parte del sistema nacional de defensores públicos.

\subsection{Fundamento jurisprudencial}

Jurisprudencialmente se destacan las siguientes sentencias de la Corte Constitucional:

\subsubsection{Sentencia SU-044 de 1995}

Con esta sentencia, en vigencia del artículo 30 del Decreto 196 de 1971, la Corte Constitucional aclaró "que aunque la norma permite confiar la defensa a quienes no son abogados titulados, ello no contraría el precepto del art. 29 en referencia, pues se debe entender que el legislador, facultado por la Constitución para determinar en qué casos se exigen títulos de idoneidad, ha habilitado especialmente al egresado de facultad de derecho que ha obtenido licencia temporal y al estudiante de derecho miembro de consultorio jurídico para actuar como defensores".

Al respecto Acosta-Madiedo acorde con lo indicado por la Corte afirma que "esto se debe a que a menos que se plasme una 
regla manifiestamente irrazonable, hace parte de la discrecionalidad del legislador la de establecer los tipos de procesos y las instancias en que puede actuar una persona todavía no graduada, y no por contemplar distinciones -que son necesarias en todo régimen excepcional- se vulnera el derecho a la igualdad alegado en esa ocasión por el actor" (2006, p. 164).

\subsubsection{Sentencia C-143 de 2001}

Como contexto de esta sentencia, es necesario tener en cuenta que:

[...] han sido recurrentes los ataques contra la existencia de los consultorios jurídicos debido al riesgo social que comporta el ejercicio de la abogacía... por ello, se cuestionaba la posibilidad de deferir el ejercicio de la profesión, por ministerio de la Ley 583/00, a un número exagerado de ingenuos estudiantes de derecho sin considerar su idoneidad, tipo de universidad, disponibilidad de recursos bibliográficos y técnicos, etc., patrocinando la irresponsabilidad e improvisación en la defensa en lugar de descongestionar los despachos judiciales (Acosta-Madiedo, 2006, p. 163).

En atención a lo referido, fue interpuesta una acción de inconstitucionalidad (parcial) en contra del artículo 1 de la Ley 583 de 2000. Sin embargo, la Corte concluyó que, el legislador al permitir que se ejerza la profesión de abogado, sin estar titulado e inscrito, lo que hizo fue desarrollar principios constitucionales que garantizan derechos como el debido proceso, la solidaridad y el acceso a la administración de justicia; en consecuencia, dejó en firme lo preceptuado en dicha ley, con la condición de que los estudiantes actúen bajo la debida supervisión, guía y control de la institución educativa a la que pertenecen.

\subsubsection{Sentencia C-110 de 2017}

En esta oportunidad, se estudió la denominación de "abogados de pobres" que ostentan los estudiantes adscritos a los consultorios jurídicos, declarándose su exequibilidad, al concluir la Corte que, con dicho término no se quebrantan principios como el de dignidad humana. Empero, dicha concepción sigue siendo cuestionable; a pesar de que se debe reconocer que a la órbita del derecho se le escapan muchas cuestiones humanas; y que el significado y peso real de las palabras no siempre puede ser establecido o delimitado desde lo jurídico, "desde el punto de vista idiomático, pobre es un término de múltiples acepciones ${ }^{4}$, de las cuales solo una o dos se refieren directamente al aspecto económico" (Velázquez, 2012, p.155).

Hasta aquí, se ha expuesto el fundamento constitucional, legal y jurisprudencial de los consultorios jurídicos, haciendo especial énfasis en el derecho de acceso a la administración de justicia por ser la piedra angular de esta investigación. En el siguiente apartado, se expondrá el desempeño del Consultorio de la UPTC en relación con el acceso a la justicia en el área laboral.

\section{ANÁLISIS DE LA EFECTIVIDAD DEL CONSULTORIO DE LA UPTC: ÁREA LABORAL 2018-2019}

Antes de presentar los resultados de esta investigación, como preámbulo, es pertinente resaltar la postura de Velázquez (2014), quien en su investigación indica que:

La obligación de los consultorios jurídicos en materia de acceso a la justicia es un tema que no ha sido estudiado con suficiente profundidad por la academia en cuanto a las cargas que impone a los estudiantes de Derecho y los consultorios jurídicos en general. Esto ha llevado a que se ignore la verdadera dimensión de esa obligación legal, con los compromisos que adquiere aquel que sea su garante, por lo cual la mayoría de las universidades, posiblemente, hayan aceptado... esta carga y orienten

4. "Necesitado, que no tiene lo necesario para vivir. Escaso, insuficiente. Humilde, de poco valor o entidad. Infeliz, desdichado y triste...." Diccionario de la RAE (2019). 
parte de sus prácticas hacia este fin, con la creencia de que, por realizar las actividades permitidas en la Ley 583 de 2000 , se satisfacen las necesidades de acceso a la justicia, cuando la realidad es muy distinta a la que crea esta norma. (p. 574).

\subsection{Objeto de estudio}

El Consultorio Jurídico Armando Suescún Monroy es un centro de extensión de la Facultad de Derecho de la UPTC, localizado en Tunja, cuyo objetivo principal gira en torno a prestar servicios de asesoría, acompañamiento judicial y extrajudicial de manera gratuita a la comunidad Boyacense ${ }^{5}$. $\mathrm{Su}$ origen se remonta a 1997 cuando la primera promoción de estudiantes de la Facultad de Derecho llegó a octavo semestre ${ }^{6}$.

"El nombre de Consultorio Jurídico Armando Suescún Monroy, fue dado, por el Consejo de Facultad... y se debe a que el docente posee una amplia trayectoria académica e histórica en la institución. De igual manera, el docente Suescún, fue el primer director del Consultorio Jurídico de la UPTC, (creador del mismo), el segundo Decano de la Facultad de Derecho, fue Rector de la UPTC, hace parte de la Academia Boyacense de Historia, Doctor Honoris causa en historia, ha escrito varios libros, no solamente en materia histórica sino del Derecho" (Dirección Jurídica UPTC, comunicación personal, 4 de marzo de 2021).

De este modo, se hace honor y reconocimiento en vida, al docente, historiador e investigador Armando Suescún; por su dedicación e innumerables aportes a la comunidad upetecista: como lo son la fundación de la Facultad de Derecho y Ciencias Sociales de la UPTC; la consolidación de la historia en general y la historia del Derecho en Colombia; autor del

5. La representación judicial está delimitada a la población perteneciente al Distrito Judicial de Tunja.

6. Este centro fue creado, aprobado y autorizado por el Acuerdo 001 de 1997 del Consejo de Facultad; la Resolución 0001 de 1998 del Tribunal Superior del Distrito Judicial de Tunja y la Resolución 0720 de 2002 del Ministerio de Justicia y del Derecho. libro de "Derecho y sociedad en la historia de Colombia", que actualmente tiene cuatro tomos; así como su invaluable aporte al desarrollo del Departamento de Boyacá y de la República de Colombia.

Ahora bien, sobre el tema en particular, en el área de Derecho Laboral los servicios del Consultorio se concretan en realizar liquidaciones laborales, adelantar procesos ordinarios laborales de única instancia, ejecutivos laborales cuya cuantía no supere 20 smlmv y procesos de acoso laboral.

\subsection{Metodología}

Para dar respuesta a la pregunta planteada y validar la hipótesis de esta investigación, se realizó un trabajo de campo en el cual se hizo una revisión del archivo del Consultorio Jurídico de la UPTC; se identificaron los procesos y liquidaciones laborales archivados entre 2018 y 2019. Se establecieron una serie de indicadores ${ }^{7}$, con los cuales se elaboró una base de datos, que integra la información obtenida de 92 carpetas; por último, se realizó la correspondiente representación gráfica y sus análisis.

\subsection{Resultados}

Tras analizar las gráficas realizadas, se logró identificar una serie de resultados y tendencias en la prestación de servicios del consultorio, información que a continuación se presenta en el siguiente orden: primero se realizará lo que se ha denominado Análisis Poblacional, con el cual se pueden identificar las características personales y sociales de los usuarios que acuden al consultorio; y, posteriormente, se realiza el Análisis de Efectividad, en el que se puede evidenciar el desempeño en la prestación de los servicios del consultorio en el área laboral.

\footnotetext{
7. Los cuales corresponden a las gráficas que se analizaron y se presentan a partir del numeral 3.3 de este trabajo, entre otros, estrato socioeconómico, tiempo de asignación, tipo de proceso, características personales.
} 


\subsubsection{Análisis poblacional}

A través de este análisis se caracterizó a los usuarios del Consultorio Jurídico de la UPTC-área laboral. Con las gráficas que componen este análisis, se pueden identificar los siguientes aspectos de la realidad social de los usuarios que solicitaron los servicios del consultorio.

\section{Gráfica 1. Municipio de residencia}

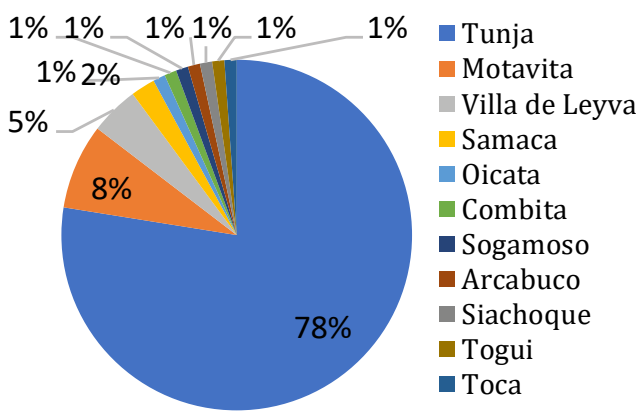

Fuente: Elaboración propia

En esta primera gráfica, se aprecia que Tunja con el setenta y ocho por ciento (78\%) representa el municipio con mayores usuarios que hacen uso de los servicios del Consultorio, le siguen en orden descendente municipios como Motavita (8\%), Villa de Leiva (5\%) y Samacá (2\%), los restantes municipios sumados representan el siete (7\%) por ciento.

Este porcentaje superior de Tunja frente al resto de municipios, es comprensible por ser este el lugar de localización de la sede física del Consultorio. Sin embargo, ese $22 \%$ restante, se puede ver como una cifra importante de población que se traslada en busca de acompañamiento jurídico.

\section{Gráfica 2. Estrato socioeconómico}

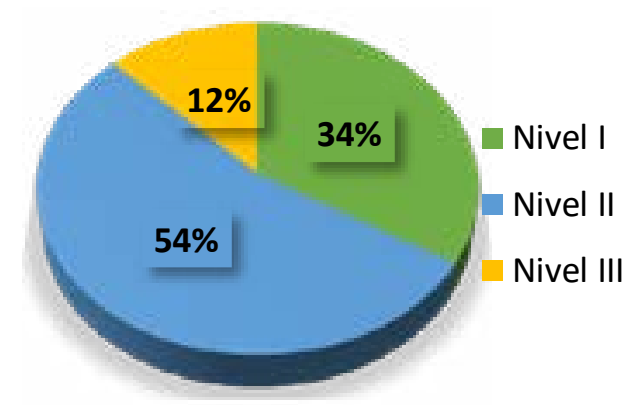

Fuente: Elaboración propia

La Ley 583 de 2000 en su artículo primero preceptúa que los estudiantes adscritos a los consultorios jurídicos de las facultades de derecho, son "abogados de pobres", por lo anterior se ha entendido que los servicios de los consultorios están destinados a las personas de los estratos 1,2 y excepcionalmente 3 , cuando estos últimos presentan declaraciones juradas de su incapacidad económica.

Dicho esto, con los resultados de la gráfica de estrato socioeconómico se observa que los usuarios del Consultorio pertenecen en su gran mayoría al nivel dos con un cincuenta y cuatro por ciento (54\%); la población de estrato uno representa el treinta y cuatro por ciento (34\%) y los usuarios nivel tres el doce por ciento $(12 \%)$. Vale destacar que, el porcentaje de usuarios nivel tres es una cifra reveladora, teniendo en cuenta que su acceso a los servicios es excepcional; quizá por eso Velázquez (2014) afirma en su investigación que la dificultad no es tener o no el dinero para pagar un abogado, pues existen otras situaciones de imposibilidad social que impiden a las personas defender sus derechos y que no se pueden leer en términos de estrato socioeconómico. 


\section{Gráfica 3. Género de los usuarios}

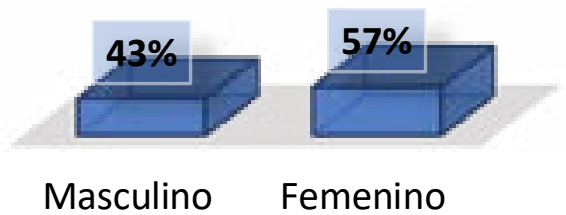

Fuente: Elaboración propia

En los usuarios del consultorio predomina la población femenina con el cincuenta y siete por ciento (57\%). Aun así, no existe una diferencia marcada con la población masculina, que equivale consecuentemente al cuarenta y tres por ciento (43\%) de los usuarios. Sin embargo, esta gráfica refleja que la población femenina, como es de amplio conocimiento, en situaciones laborales sigue siendo la menos favorecida.

\section{Gráfica 4. Características personales}

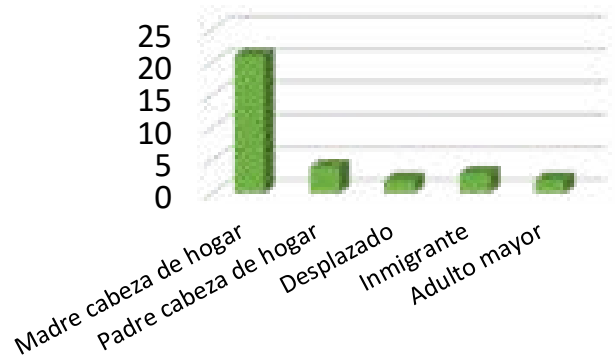

Fuente: Elaboración propia

Igualmente, dentro de los procesos analizados se encontraban diferentes sujetos de especial protección, las cifras son las siguientes: veintiún (21) usuarias eran madres cabezas de hogar, cuatro (4) usuarios eran padres cabeza de hogar, dos (2) personas se encontraban en situaciones de desplazamiento, tres (3) de los usuarios eran inmigrantes y dos (2) eran adultos mayores.

Esta gráfica tiene particular importancia, pues indica que el treinta y cuatro por ciento (34\%) de los usuarios, además de ser población de bajos recursos, presenta alguna condición específica de vulnerabilidad, lo que evidencia la existencia de otros factores que pueden hacer más gravosa la situación de los usuarios que buscan acceder a la administración de justicia a través del Consultorio.

\section{Gráfica 5. Edad al momento de acudir al consultorio}

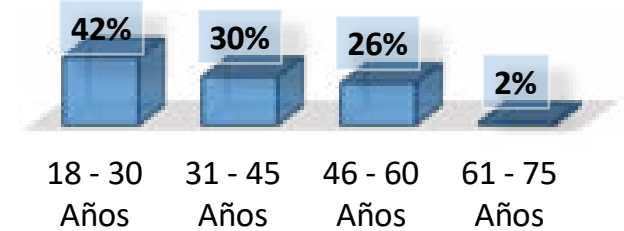

Fuente: Elaboración propia

Los resultados de esta gráfica, en principio se diría que no son lógicos por ubicarse en los niveles superiores la población entre 18 y 45 años; sin embargo, entendiendo la realidad social del departamento, con esta gráfica se evidencia que la afluencia de personas mayores de 60 años al Consultorio es mínima, lo cual indica que no se está llegando a una población tan vulnerable, como lo es el adulto mayor ${ }^{8}$.

\section{Gráfica 6. Nivel de escolaridad}

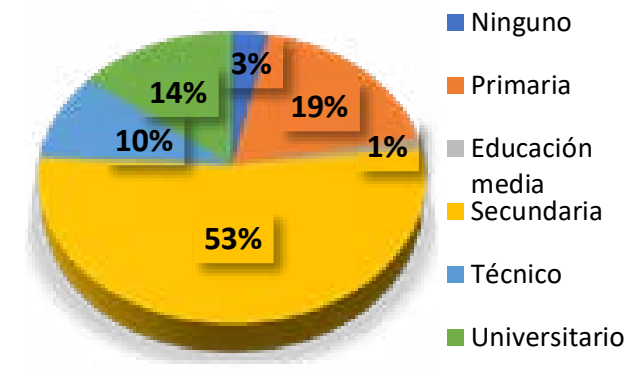

Fuente: Elaboración propia

8. Ver Boyacá 7 Días. (10 de julio de 2019). “La población boyacense cuenta con un $71,47 \%$ de personas mayores de 60 años". 30 de cada 100 boyacenses son adultos mayores de 60 años. 
Se dice que, las personas que no pueden acceder a la educación superior en sí ya son relativamente vulnerables en el campo laboral. Pues bien, en esta gráfica se aprecia que el setenta y seis por ciento (76\%) de usuarios no cuentan con educación superior, solo con secundaria o básica primaria y el veinticuatro por ciento (24\%) de los usuarios que acudieron tenían algún tipo de formación universitaria o técnica.

\section{Gráfica 7. Ocupación de los usuarios}

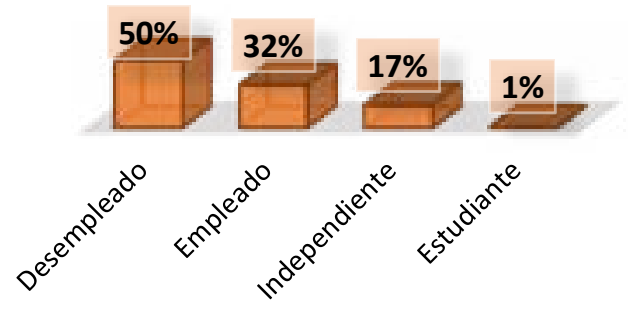

Fuente: Elaboración propia

De acuerdo con los datos analizados, el cincuenta por ciento (50\%) de los usuarios se encontraban desempleados, condición que los deja en situación de mayor vulnerabilidad. De igual manera, se resalta que hay muchas actividades, que no requieren sólo del recurso humano de los consultorios sino también recursos financieros (pago de copias, certificaciones, notificaciones, emplazamientos, etc.) y muchas de esas diligencias truncan la evolución de los procesos; no existe una regulación efectiva ${ }^{9}$ que establezca cómo solucionar este tipo de impases, motivo por el cual los usuarios muchas veces desisten de sus pretensiones.

Hasta este punto, se han analizado las características sociales de los usuarios del área laboral que acudieron al Consultorio

9. Anaya (2016) en su investigación concluye sobre el Amparo de Pobreza que "aun cuando la intención del legislador fuera eximir al amparado de todos los gastos procesales que le impidan tener una resolución efectiva del conflicto presentado, no hay vías concretas y funcionales para que en la práctica sea de esa manera" (p. 21).
Jurídico de la UPTC entre 2018 y 2019. A continuación, se evalúa el nivel de efectividad que tuvo el Consultorio en cuanto a la garantía de acceso a la administración de justicia para aquellos usuarios.

\subsubsection{Análisis de efectividad}

El estudio de los gráficos que a continuación se presentan, resulta de gran importancia para evaluar el desempeño que tuvo el consultorio jurídico en cuanto a la materialización del derecho a acceder a la administración de justicia; el cual resulta pertinente reiterar, no se entiende agotado con el mero diseño normativo para su operatividad, sino que persigue la materialización efectiva del derecho sustancial (Sentencia C-420 de 2020).

\section{Gráfica 9. Tiempo de asignación}

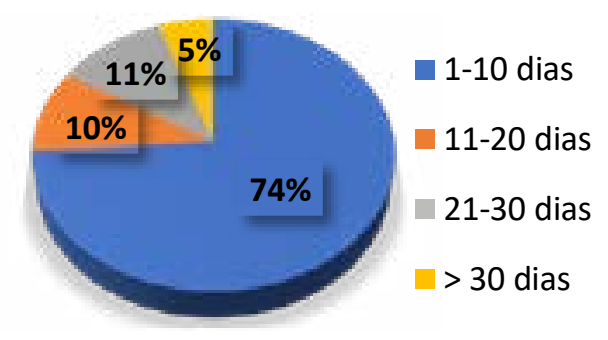

Fuente: Elaboración propia

Para analizar adecuadamente esta gráfica, se debe tener en cuenta que de acuerdo con el funcionamiento interno del Consultorio Jurídico de la UPTC, después de recepcionada la solicitud de servicios, por regla general, semanalmente se realiza un reparto de asignación entre sus estudiantes adscritos. Asimismo, en estos tiempos de asignación influyen aspectos como vacaciones 0 suspensiones académicas.

Aclarado lo anterior, con la gráfica de tiempos de asignación, se vislumbra que, en el tiempo transcurrido entre la fecha de la solicitud y el tiempo de asignación del proceso por parte del Consultorio al respectivo estudiante, predomina el lapso 
entre uno y diez días con el setenta y cuatro por ciento $(74 \%)$. El veintiséis por ciento (26\%) restante se asigna en un tiempo superior a diez días.

\section{Gráfica 9. Tipo de consulta}

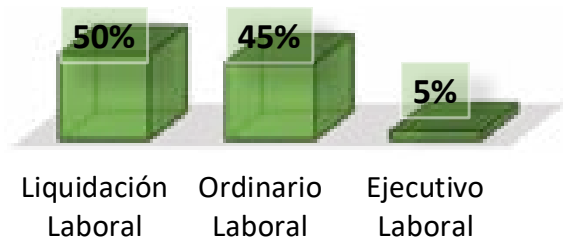

Fuente: Elaboración propia

Con esta gráfica, se puede categorizar el posicionamiento de los servicios prestados en el área laboral. El servicio por el que mayormente recurren los usuarios al consultorio en el área laboral es para la realización de liquidaciones laborales, las cuales están representadas con el cincuenta por ciento (50\%); en segunda posición, se encuentran los procesos ordinarios laborales con un cuarenta y cinco por ciento (45\%); $\mathrm{y}$, en el último lugar, se hallan los procesos ejecutivos laborales, que en relación con los mencionados anteriormente son mínimos al contar solamente con el cinco por ciento $(5 \%)$.

Entendiendo la naturaleza del servicio dominante, la anterior información es de gran importancia pues se aprecia que de los usuarios del área laboral que se acercaron al consultorio, solo el 50\% lo hizo con miras de acceder propiamente a la administración de justicia, los demás solo aspiraron a obtener una labor técnica.

\section{Gráfica 10. Tiempo de entrega de liquidación laboral}

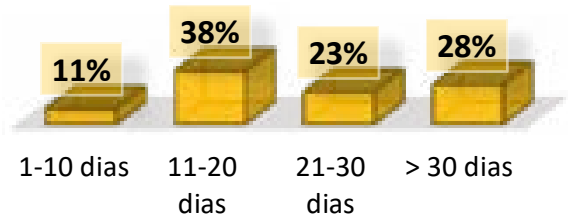

Fuente: Elaboración propia
Es necesario resaltar que, a pesar de que las liquidaciones son un procedimiento relativamente sencillo, por cuanto su realización no requiere mayor tiempo; según la gráfica, se evidencia que solo el once por ciento (11\%) fueron realizadas y entregadas en un término más o menos razonable ${ }^{10}$. Cabe aclarar que muchas veces los datos consignados en la solicitud de servicio resultan incompletos; por esta razón, el usuario debe ser contactado para que proporcione la totalidad de la información; entonces, la entrega oportuna de la liquidación dependerá del tiempo de obtención de los datos requeridos.

En adición a lo anterior, resulta pertinente denotar el sistema burocrático que para el caso, prima en el Consultorio, pues el estudiante debe asistir en los horarios y fechas establecidos a la asesoría especializada para la verificación de la liquidación ${ }^{11}$. Es decir que si el estudiante no puede acogerse a una de las fechas fijadas, automáticamente se dilatará el procedimiento. Tratándose de una labor técnica, el consultorio debería facultar a uno de los asesores permanentes para que haga la revisión y autorice la entrega de la liquidación.

\section{Gráfica 11. Motivo de archivo de las liquidaciones laborales}

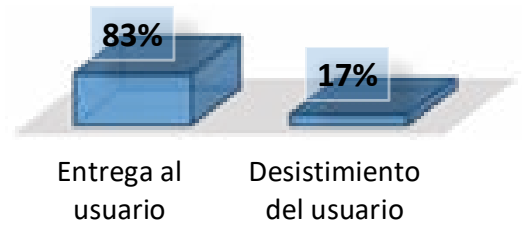

Fuente: Elaboración propia

10. Se ha considerado más o menos razonable el término de 1 a 10 días, en consideración al tipo de procedimiento, el cual se basa en la aplicación de fórmulas matemáticas plenamente establecidas, lo que implicaría un resultado automático en los casos en que los datos necesarios son precisos.

11. El Consultorio por área de competencia, tiene designado un asesor profesional especializado y presta su acompañamiento a todos los estudiantes que llevan procesos del área durante dos horas, dos veces a la semana. 
En cuanto al resultado final de las liquidaciones laborales, con esta gráfica se evidencia que el ochenta y tres por ciento $(83 \%)$ de estas fueron entregadas a sus solicitantes, mientras que el restante diecisiete por ciento $(17 \%)$ fueron archivadas debido al desistimiento de los usuarios.

\section{Gráfica 12. Duración de los procesos ejecutivos laborales}

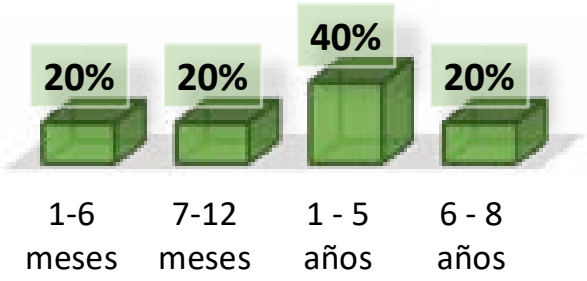

Fuente: Elaboración propia

Respecto a la duración de los procesos ejecutivos laborales, se aprecia con esta gráfica que, en la tramitación de los mismos desde la fecha de solicitud hasta la fecha de archivo, priman una de las más altas, esto es de uno a cinco años.

Gráfica 13. Motivo de archivo de los procesos ejecutivo laborales:

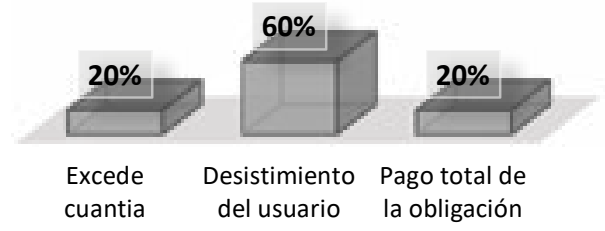

Fuente: Elaboración propia

Entendiendo la naturaleza especial de los procesos ejecutivos laborales y la relevancia que tiene la capacidad económica de la parte ejecutada, resulta comprensible la imposibilidad muchas veces de resultados satisfactorios; sin embargo, teniendo en cuenta los tiempos de duración presentados en la gráfica anterior, que un sesenta por ciento $(60 \%)$ sean archivados por desistimiento de los usuarios, es claramente un resultado poco alentador.

\section{Gráfica 14. Duración de los procesos ordinario laborales}

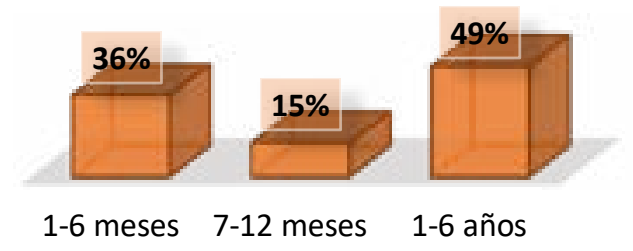

Fuente: Elaboración propia

Respecto a los procesos ordinarios laborales, existen dos tendencias predominantes en cuanto a la duración. Con los resultados se evidencia que el cuarenta y seis por ciento (46\%) de estos procesos tienen una duración entre uno y seis años; la otra parte que destaca, se encuentra dentro de uno a seis meses con el treinta y seis por ciento (36\%). Solo el quince por ciento $(15 \%)$ ha tenido una duración de siete meses a un año.

Gráfica 15. Motivo de archivo de los procesos ordinarios laborales.

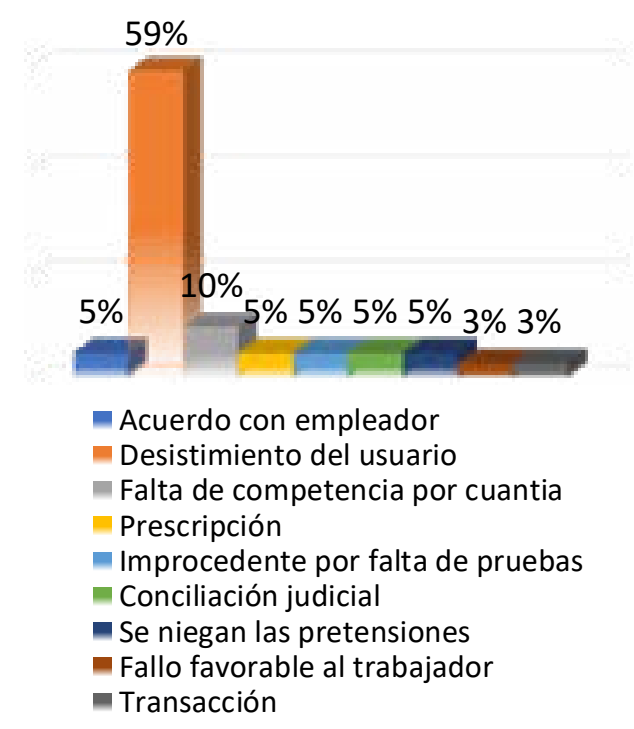

Fuente: Elaboración propia 
En relación con el acceso efectivo a la administración de justicia, con esta gráfica se evidencia que solo el trece por ciento (13\%) llegó a la jurisdicción, obteniendo como resultado: un acuerdo conciliatorio el cinco por ciento (5\%), a otro cinco por ciento (5\%) se le negaron las pretensiones y solamente el tres por ciento (3\%) obtuvo un fallo favorable.

El fenómeno de la prescripción se presentó en un cinco por ciento (5\%). Sobre un diez por ciento $(10 \%)$ de los procesos, el Consultorio no tenía competencia por superar la cuantía límite establecida. El cinco por ciento (5\%) logró un acuerdo extrajudicial con el empleado y el tres por ciento $(3 \%)$ una transacción. Un cinco por ciento $(5 \%)$ resultó improcedente por falta de pruebas.

Definitivamente, los resultados de esta gráfica son dicientes para esta investigación, claramente se puede apreciar que el cincuenta y nueve por ciento (59\%) de los procesos ordinarios laborales fueron archivados debido al desistimiento del usuario, su aspiración inicial al transcurrir el tiempo fue abandonada sin haber recibido solución alguna.

\section{CONCLUSIONES}

La presente investigación se ha dedicado al estudio del acceso efectivo de la administración de justicia de las personas en situación de vulnerabilidad como objetivo trascendental de los consultorios jurídicos. En particular, se analizó la efectividad que tuvo entre 2018 y 2019 el Consultorio Jurídico Armando Suescún Monroy para con los usuarios del área laboral. En el desarrollo del trabajo, se logró establecer el origen y finalidades para las cuales fueron creados los consultorios jurídicos; los cuales son sin duda alguna cruciales para un ordenamiento jurídico que se soporta en principios como lo son dignidad humana, solidaridad y justicia social. Se evidenció que, los estudiantes adscritos a los consultorios jurídicos cumplen una importante función al brindar acompañamiento judicial gratuito a las personas menos favorecidas; al mismo tiempo, los educandos adquieren habilidades y destrezas para su desempeño profesional.

Además, se demostró que el concepto actual de acceso a la justicia ha evolucionado. Con fundamento en preceptos constitucionales, legales, jurisprudenciales, la normativa internacional y el análisis doctrinal, se ha concluido que, no basta con reconocer la existencia del derecho de acción, sino que se debe buscar su materialización. El sistema de justicia debe contar con mecanismos adecuados y sencillos que garanticen una resolución de fondo, que no implica la existencia siempre de un fallo favorable, sino el pronunciamiento, ajustado al derecho y dentro de un plazo razonable, sobre la existencia o no de la pretensión reclamada.

Dentro del análisis realizado sobre el Consultorio Jurídico Armando Suescún Monroy, se puede evidenciar que este centro está atendiendo en su mayoría a las personas consideradas desfavorecidas económicamente por pertenecer al estrato socioeconómico uno y dos. Sin embargo, se evidenció también, que dentro de los usuarios existe un gran número de los catalogados como no desfavorecidos al pertenecer al estrato tres, lo cual indica que las necesidades reales no pueden medirse de acuerdo con las clasificaciones, muchas veces contrarias a la realidad social.

Asimismo, se determinó el nivel de efectividad del Consultorio Jurídico en cuanto al acceso a la justicia. Los resultados del área laboral son poco favorables, el servicio más solicitado no requiere propiamente acceder a la administración de justicia y aquellos que son objeto de litigio, en su mayoría y luego de un largo tiempo de tramitación, son archivados por desistimiento de los usuarios; penosamente son muy pocos los que terminan satisfactoriamente.

Se confirmó así en esta investigación, que la labor del Consultorio Jurídico de la UPTC en el área laboral, en cuanto a la garantía de acceso a la administración de justicia, se está quedando en lo meramente formal. 
Sin políticas públicas adecuadas y una reglamentación consolidada; así como su correcta implementación en los establecimientos educativos de educación superior. Asegurar a las personas en situación de vulnerabilidad el acceso a la justicia, es una finalidad utópica para los Consultorios Jurídicos, pues son ampliamente debatibles las obligaciones y regulaciones que existen para estos centros. La realidad social de los usuarios que hacen uso de los servicios del consultorio, muestra que no es suficiente la designación de un estudiante en representación de un usuario, para que efectivamente se puedan eliminar los obstáculos que conlleva acceder a la administración de justicia.

\section{RECOMENDACIONES}

Como se dejó establecido desde el inicio de este artículo, una de las principales finalidades de este trabajo era proyectar necesidades de cambio y así lograr una mejora en el desempeño del Consultorio Jurídico de la UPTC. Aunque los factores que desencadenaron los resultados presentados pueden ser diversos y considerables, se debe buscar el mejoramiento del servicio, enfocándose en garantizar efectivamente el acceso a la justicia, para lo cual se debe propender por un adecuado manejo, regulación ${ }^{12}$ y financiamiento para este centro de extensión.

12. Cabe aclarar que en el Congreso de la República se está desarrollando un proyecto de Ley (No. 275 de 2019 Senado y No. 007 de 2019 Cámara), con el que se busca regular el funcionamiento de los consultorios jurídicos; lo cual es oportuno ya que hasta el momento no existe una ley que regule de manera específica el funcionamiento de estos centros. Del texto aprobado en segundo debate por la Cámara de Representantes, de manera general se puede vislumbrar que uno de los principales objetivos del proyecto es ampliar la competencia o rango de acción de los consultorios; sin embargo, respecto a nuestra área de estudio -laboral-, no se advierten cambios sustanciales.
En consecuencia, se recomienda reestructurar el funcionamiento del Consultorio, buscando eliminar aquellas falencias en la prestación de los servicios. Para ello resulta indispensable, primero que todo, establecer un reglamento interno y un manual de funcionamiento, como bien lo indica nuestra Carta Superior.

Ahora bien, específicamente para el área laboral, es necesario asegurar un acompañamiento continuo, garantizando de un asesor de tiempo completo, si la cantidad de estudiantes así lo exige. Por otra parte, sería ideal que el consultorio promoviera espacios de retroalimentación para que los estudiantes den a conocer sus experiencias ante la jurisdicción, así mismo respecto a la percepción de los usuarios.

Igualmente, es necesario que en el Consultorio se dé cumplimiento a Ley General de Archivo (Ley 594 de 2000) y a la Ley de Transparencia y del Derecho de Acceso a la Información Pública (Ley 1712 de 2014). En el desarrollo del trabajo de campo se evidenció que no existe un adecuado sistema de gestión documental, el cual resulta indispensable para facilitar la gestión de la información y, en suma, la gestión del conocimiento en el Consultorio.

Por último, dada la trascendencia que tienen los consultorio jurídicos en la materialización de los principios de nuestro Estado Social de Derecho y de los derechos fundamentales de las personas en situación de vulnerabilidad, con este trabajo pretendemos abrir la puerta a futuras investigaciones, en las que se realicen análisis profundos y detallados del consultorio, respecto a su efectividad en la prestación de los servicios y su impacto tanto en las comunidades como en la formación de sus estudiantes adscritos. 


\section{ANEXOS}

Anexo 1. Consultorios jurídicos y clínicas jurídicas en Colombia. Armando Suescún Monroy

\begin{tabular}{|c|c|c|}
\hline & $\begin{array}{c}\text { Regulsdon de los con sultorios } \\
\text { juridices }\end{array}$ & Las elinieas juridieas \\
\hline $\begin{array}{l}\text { Aprobacien } \\
\text { para miciar } \\
\text { fubcionamiento }\end{array}$ & $\begin{array}{l}\text { La normatividad exige que d consulterio } \\
\text { sea "sprobado por el Tribunal Superior de } \\
\text { Distrito Judicia donde funcione la } \\
\text { repectiva facultad" (Ley } \$ 33 \text { de 2000). }\end{array}$ & $\begin{array}{l}\text { Han existido diversas opciones: } \\
\text { Aprobaci on eomo asignatura electiva por la } \\
\text { facultad. } \\
\text { Trabajo voluntario. } \\
\text { Lises de investigacion para grado aprobada } \\
\text { por la facul tad. } \\
\text { Inclusión como parte dd consultorio } \\
\text { juridico (area o estructura similar). }\end{array}$ \\
\hline $\begin{array}{l}\text { Tipologia de } \\
\text { servichdelos } \\
\text { estodiantes }\end{array}$ & 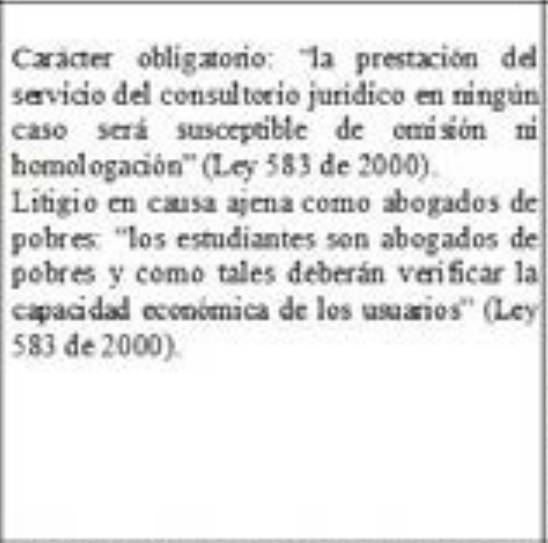 & 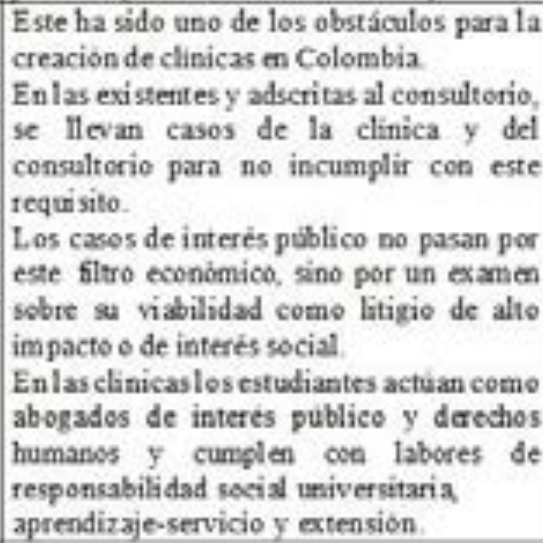 \\
\hline $\begin{array}{l}\text { Dirección ded } \\
\text { servicio }\end{array}$ & $\begin{array}{l}\text { El director del consul torio debe ser tm } \\
\text { "abogado titulado debicado exclusivamente } \\
\text { al consultorio, con experiencia en docencia } \\
\text { universitaria o practica profesional no } \\
\text { inferiot a cinco (5) atos". Debe "gercer a } \\
\text { proforado en la facultad o ser abogado de } \\
\text { pobres del Servicio Juridico Popular" } \\
\text { (Decteto } 765 \text { de } 1977 \text { ). }\end{array}$ & $\begin{array}{l}\text { La dirección de la clinica la ejerce un } \\
\text { abogado túblado, docente universitario con } \\
\text { dedicación exclusiva o parcial en algunas } \\
\text { univer sidades. }\end{array}$ \\
\hline $\begin{array}{l}\text { Dirección } \\
\text { administrativa }\end{array}$ & $\begin{array}{l}\text { Si se tienen mas de } 100 \text { alumnos, deben } \\
\text { contar con esta dirección. }\end{array}$ & $\begin{array}{l}\text { No la tienen, salvo que compartan la que } \\
\text { existe en d consultorio jundico. }\end{array}$ \\
\hline $\begin{array}{l}\text { Asporesen } \\
\text { derekho pubjico, } \\
\text { pesalprivado y } \\
\text { laboral }\end{array}$ & 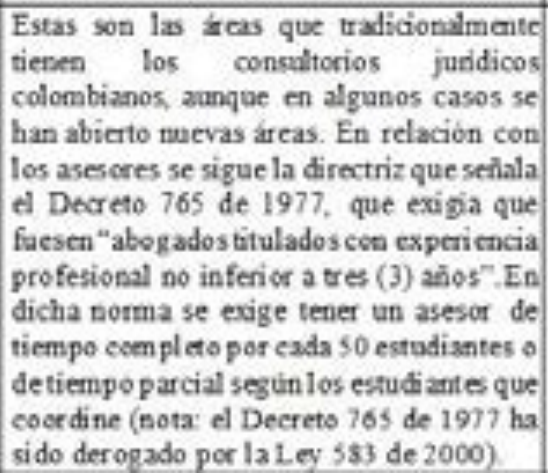 & $\begin{array}{l}\text { Se denominan supervisores y cumplen la } \\
\text { laborde aseseriadirectaalos estudiantes en } \\
\text { los casos que asume la dinica. Segun la } \\
\text { experiencia de las dinicas se observa que } \\
\text { son abogados titulados con experiencia en } \\
\text { el áreadela dinaca. Serecomiendaal menos } \\
\text { un supervisor de tiempo completo por cada } \\
\text { diez estudiantes. }\end{array}$ \\
\hline
\end{tabular}




\begin{tabular}{|c|c|c|}
\hline Monitores & $\begin{array}{l}\text { Son egrefados, o alumnos de ultime aho de } \\
\text { la carera. Se exige tno por cada } 20 \\
\text { alumnes. }\end{array}$ & $\begin{array}{l}\text { En los casos en que la clinica exd sdscrita } \\
\text { al consultorio juridico se cuenta con un } \\
\text { monitos. }\end{array}$ \\
\hline $\begin{array}{l}\text { Condiciones } \\
\text { locativasy } \\
\text { logisticas } \\
\text { adfeuadas }\end{array}$ & $\begin{array}{l}\text { Lainstitucion debe "disponer de locales en } \\
\text { condiciones adecuadas para d trabajo de los } \\
\text { profesores, monitores y alumnos, y maebles. } \\
\text { biblisteca y equipos suficientes para el } \\
\text { funcionamiento de consultorio". }\end{array}$ & $\begin{array}{l}\text { La clinica exige de tas condiciones } \\
\text { locativas adecuadas, sala de rearión para } \\
\text { todo a grupo, equipos y recursos para la } \\
\text { labor que adelasta. }\end{array}$ \\
\hline $\begin{array}{c}\text { Dedicacion de bs } \\
\text { alumnos }\end{array}$ & $\begin{array}{l}\text { Por lo menos dos semestres en los dos } \\
\text { ultimos aros de la carrera. }\end{array}$ & $\begin{array}{l}\text { Por lo menos dos semestres en los dos } \\
\text { últimos anos de la carrera. }\end{array}$ \\
\hline Competencias & 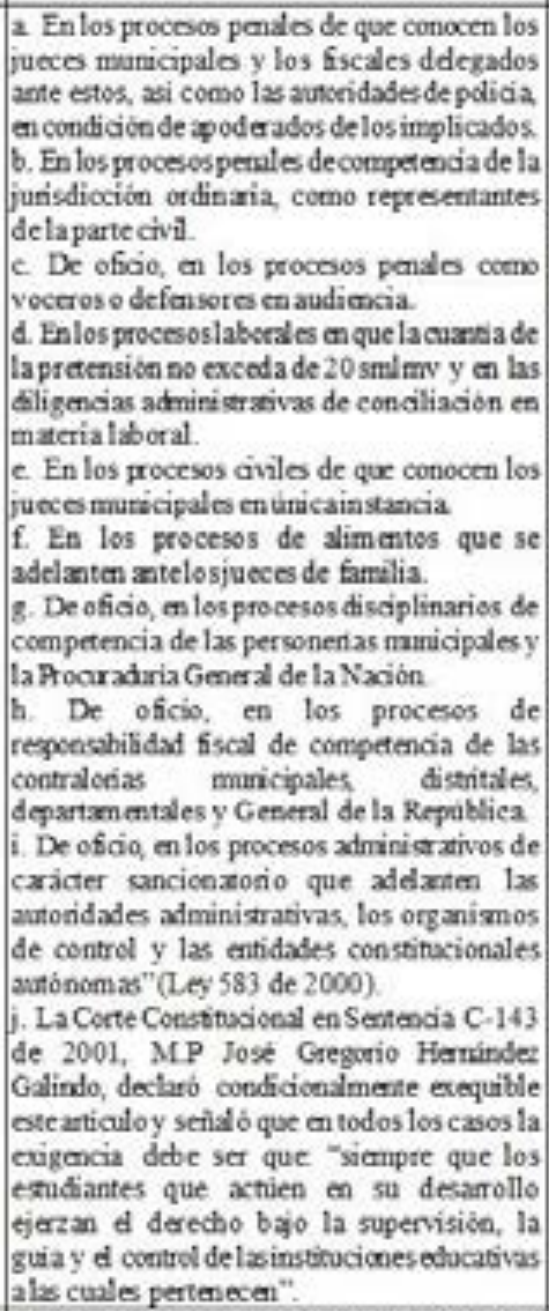 & 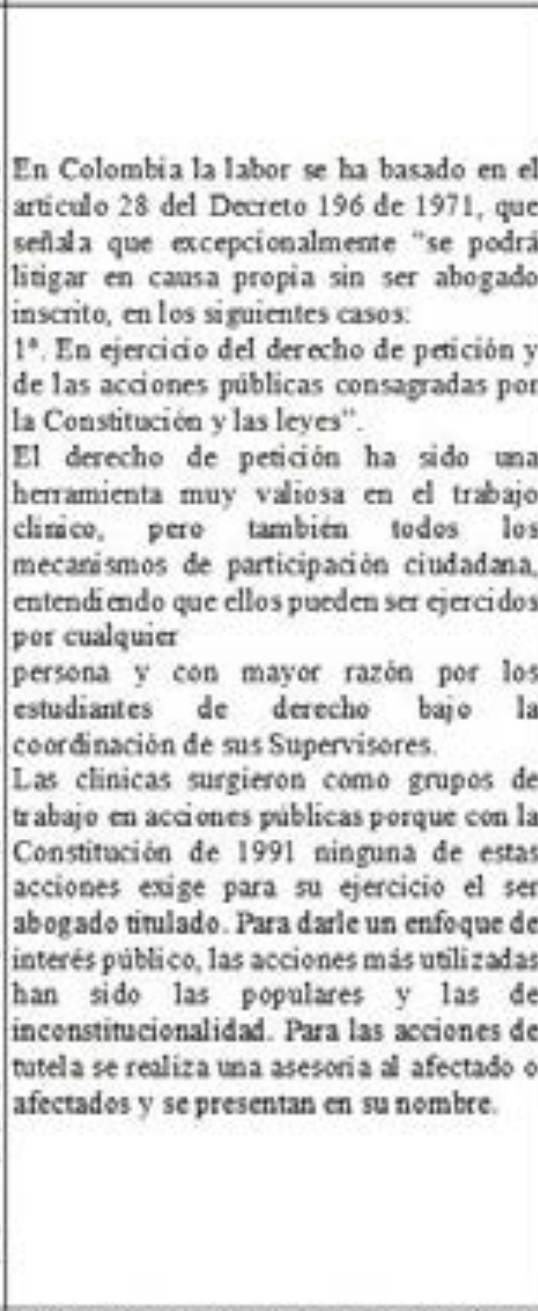 \\
\hline $\begin{array}{c}\text { Exigencia para } \\
\text { as acruacioees } \\
\text { debs } \\
\text { estudiantes }\end{array}$ & $\begin{array}{l}\text { Autorizacion del consultorio jundico para } \\
\text { redizar las respectivas actuaciones judicialesy } \\
\text { administravivas. }\end{array}$ & $\begin{array}{l}\text { Comoreglageneal, en todas las actuaciones } \\
\text { judiciales se induye la autorización del } \\
\text { consultserio juridico y la mendice de } \\
\text { pertenecer a La clinica juridica. }\end{array}$ \\
\hline
\end{tabular}

Fuente: Beatriz Lodoño (2015) 


\section{REFERENCIAS BIBLIOGRÁFICAS}

»Acosta-Madiedo, C. (2006). Estatuto del Abogado: El porqué de lo polémico. Universitas Estudiantes, 3, pp.157-188.

» Anaya, M. (2016). El amparo de pobreza en Colombia como garantía efectiva del derecho al acceso a la administración de justicia. [tesis de pregrado, Universidad de los Andes]. Repositorio Institucional. https://repositorio.uniandes.edu.co/

» Boyacá 7 Días. (10 de julio de 2019). "La población boyacense cuenta con un $71,47 \%$ de personas mayores de 60 años". 30 de cada 100 boyacenses son adultos mayores de 60 años. Disponible en: https://boyaca7dias.com.co/

» Barreto. M. y Sarmiento, L. (1997). Título II. En Constitución Política de Colombia comentada por la Comisión Colombiana de Juristas. Comisión Colombiana de Juristas, pp. 1-461.

» Bonilla, D. (2018). Consultorios Jurídicos: Educación para la democracia. En Bonilla (Ed.), Abogados y justicia social: derecho de interés público y clínicas jurídicas, Ediciones Uniandes -Siglo del Hombre Editores, pp. 17-110.

» Castro-Buitrago, E., Espejo-Yaksic, N., Puga, M., y Villarreal, M. (2011). Clinical Legal Education in Latin America: Toward Public Interest. En The Global Clinical Movement: Educating Lawyers for Social Justice. Universidad de Oxford, pp. 69-86.

» Congreso de la República de Colombia. (2000,13 de junio). Ley 583. Por la cual se modifican los artículos 30 y 9 del Decreto 196 de 1971. Diario Oficial 44042. Disponible en: http://www.suin-juriscol.gov.co/viewDocument.asp?ruta=Leyes/1662987

» Congreso de la República de Colombia. (2005, 14 de enero). Ley 941. Por la cual se organiza el Sistema Nacional de Defensoría Pública. Diario Oficial 45791. Disponible en: http://www.suin-juriscol.gov.co/viewDocument.asp?ruta=Leyes/1671540

» Corte Constitucional. (1992, 26 de octubre). Sentencia T-572. (Jaime Sanín Greiffenstein, M.P.). Disponible en: https://www.corteconstitucional.gov.co/ relatoria/2020/C-037-20.htm

» Corte Constitucional. (1995, 9 de febrero). Sentencia SU 044. (Antonio Barrera Carbonell, M.P.). Disponible en: https://www.corteconstitucional.gov.co/relatoria/1995/SU044-95.htm

» Corte Constitucional. (1996, 18 de junio). Sentencia T-268. (Antonio Barrera Carbonell, M.P.). Disponible en: https://www.corteconstitucional.gov.co/ relatoria/1996/T-268-96.htm

» Corte Constitucional. (1996, 5 de febrero). Sentencia C-037. (Vladimiro Naranjo Mesa, M.P.). Disponible en: https://www.corteconstitucional.gov.co/ relatoria/2020/C-037-20.htm

» CorteConstitucional.(2001,7 defebrero).SentenciaC-143.(GregorioHernández Galindo, M.P.) https://www.corteconstitucional.gov.co/relatoria/2001/C-143-01. htm

» Corte Constitucional. (2011, 21 de octubre). Sentencia T-799. (Humberto Antonio Sierra Porto, M.P.). Disponible en: https://www.corteconstitucional.gov.co/ relatoria/2011/T-799-11.htm 
» Corte Constitucional. (2017, 22 de febrero). Sentencia C-110. (Alberto Rojas Ríos, M.P.). Disponible en: https://www.corteconstitucional.gov.co/ relatoria/2017/C-110-17.htm

» Corte Constitucional. (2020, 24 de septiembre). Sentencia C-420. (Richard S. Ramírez Grisales M.P.). Disponible en: https://www.corteconstitucional.gov.co/ relatoria/2020/C-420-20.htm\#_ftn435

» Duque, S, González, \& Quintero, M. (2012). La popularización del derecho en el consultorio jurídico: una apuesta por una educación jurídica con relevancia social. Revista Estudios de Derecho, 2, pp. 45-63.

» Echandía, D. (2012). Teoría general del proceso (3ª ed.). Editorial Universidad.

» García Añón, J. (2014). Transformaciones en la docencia y el aprendizaje del derecho: ¿La educación jurídica clínica como elemento transformador? Teoría \& Derecho, 15, pp. 12-33.

» González, J. (s.f.). El discreto aporte del derecho. Universidad de Antioquia.

» La Rota, M., Lalinde, S., Santa, S., Uprimny, R. (2014). Ante la justicia: Necesidades jurídicas y acceso a la justicia en Colombia. Colección Dejusticia.

» Lodoño, B. (2015). Educación legal clínica y litigio estratégico en Iberoamérica. Universidad del Rosario.

» Madrid-Malo, M. (1998). Preámbulo, Títulos I y XIII. En Constitución Política de Colombia comentada por la Comisión Colombiana de Juristas. Comisión Colombiana de Juristas, pp. 1-136.

» Presidencia de la República. (1971, 10 de marzo). Decreto 196. Por el cual se dicta el estatuto del ejercicio de la abogacía. 10 de marzo de 1971. Diario Oficial 33255. Disponible en: http://www.suin-juriscol.gov.co/viewDocument. asp?ruta=Decretos $/ 1044523$

» Presidencia de la República. (1977, 29 de abril). Decreto 765. Por el cual se reglamentan los artículos 30, 31 y 32 del Decreto-Ley 196 de 1971, y se regula la prestación de servicio profesional para optar al título de abogado. Diario Oficial 34775. Disponible en: http://www.suin-juriscol.gov.co/viewDocument. asp?ruta=Decretos $/ 1161656$

» Presidencia de la República. (1979, 21 de diciembre). Decreto 3200. Por el cual se dictan normas sobre la enseñanza del Derecho. Diario Oficial 35444. Disponible en: https://www.funcionpublica.gov.co/eva/gestornormativo/norma. php?i=81515

» Real Academia Española. (2019). Diccionario. Disponible en: https://dle.rae. es/.

» Recalde, G, Luna, T, y Bonilla, D. (2017) Justicia de pobres: Una genealogía de los consultorios jurídicos en Colombia. Revista de Derecho, 47, pp. 1-72.

» Silva, M. (2013). Módulo Sobre Integración del Código General del Proceso al Proceso del y Trabajo y la Seguridad Social. Escuela Judicial Rodrigo Lara Bonilla. 
» Thea, F. (2012). Artículo 8. Garantías judiciales. En La Convención Americana de Derechos Humanos y su proyección en el Derecho Argentino Universidad de Buenos Aires, pp.127-166.

» Thome, J. (1984). New Models for Legal Services in Latin America. Human Rights Quarterly, 6(4), pp. 521-538.

» Velásquez, H. (2012). Críticas a las competencias de los consultorios jurídicos a la luz del Decreto 196 de 1971 y la Ley 583 de 2000. [tesis de maestría, Universidad Pontificia Bolivariana]. Repositorio Institucional. Disponible en: https:// repository.upb.edu.co/

» Velásquez, H. (2014). Prácticas de consultorio jurídico y aporte para el acceso a la justicia. Revista Facultad de Derecho y Ciencias Políticas, 44 (121), pp. 551-576. 